\title{
Treatment of breast cancer in elderly patients
}

\section{E Zappulla, V Russo, I Gullotta, G Patanè, S Trovato, B Lucifora, S Costa, A Tracia, P Caglià and C Amodeo*}

\author{
Address: Department of Surgical Sciences, Organ Transplantation and Advanced Technologies, Surgery Oncology Unit, University of Catania, Italy \\ * Corresponding author
}

from XXI Annual Meeting of The Italian Society of Geriatric Surgery

Terni, Italy. 4-6 December 2008

Published: I April 2009

BMC Geriatrics 2009, 9(Suppl I):A57 doi:10.1 186/I47|-23 I8-9-SI-A57

This abstract is available from: http://www.biomedcentral.com/I47I-23 I8/9/SI/A57

(C) 2009 Zappulla et al; licensee BioMed Central Ltd.

\section{Objectives}

The number of elderly patients with breast cancer is increasing. The purpose of this study was to evaluate the outcome of treatment of elderly women with breast cancer. We have explored the clinical and biologic characteristics of a group of patients aged 65 years and over affected with breast cancer. We have also identified specific subsets of elderly patients with breast cancer who have survival similar to that expected in the general population irrespective of disease status.

\section{Materials and methods}

We considered 155 patients aged 65 year and over, with an average of 74.1 year (range 65-87), treated at the Department of Surgical Sciences, Organ Transplantation and Advanced Technologies, Oncology Surgery Unit, University of Catania, Italy. The therapeutic outcome was established after the evaluation of the breast cancer's stage, according to the TNM classification. Thirty patients of the 155 belonged to the I stage, 40 to the II, 67 to the III and 18 to the IV stage. For T1 or T2 tumors we performed a quadrantectomy, followed by radiotherapy treatment on the residual breast tissue. For T3 tumors it has been performed a modified radical mastectomy, while in $\mathrm{T} 4$ we opted for a primary chemotherapy followed by a modified radical mastectomy for patients $\mathrm{M} 0$, or simple mastectomy for those M1.

\section{Results}

The most frequent histological aspect of breast cancer was lobular, tubular and mucinous cancer, as well as mixed ductal-lobular. The positivity for hormone receptors (ER) was $74 \%$ (111 patients). According to the pathological and biological features, and after oncological evaluation, patients underwent adjuvant chemotherapy (CMF, FEC) and/or hormonal therapy (tamoxifen). The average follow-up has been 50 months (range 12-78). We found a rebound of disease in 43 patients $(28.6 \%)$, with a 17 months medium disease-free period. Ten local recurrences, all in patients who underwent quadrantectomy, have been detected.. Three patients had local recurrence associated with lung metastases. No axillary recurrence has been found in patients who had axillary node dissection. The perioperative mortality was $0 \%$ and there was a $18.6 \%$ mortality in five years.

\section{Conclusion}

Standard treatment for breast cancer usually involves multi-modality treatment with a combination of surgery and adjuvant therapies. These may include chemotherapy, radiotherapy, endocrine therapy. The elderly receive less aggressive treatment for breast cancer compared with younger patients. Primary endocrine therapy is sometimes substituted for operation, and axillary surgery, adjuvant chemotherapy and adjuvant radiotherapy are commonly omitted. Although most breast cancer patients are diagnosed at $>65$ years, historically an arbitrary cut-off of 70 years has been widely used, above which women were considered for Tamoxifen-only treatment.

Older age is the most important risk factor for breast cancer, and because gains in life expectancy, particularly at the end of life, will result in more women being at risk for longer periods. Although available age-specific clinical tri- 
als data demonstrate that treatment efficacy is not modified by age, this efficacy evidence is limited by the lack of inclusion of substantial numbers of older women, particularly those of advanced age and those with comorbidities. Our preliminary work has demonstrated correlation between ER positivity and lower local recurrence (especially when treated with Tamoxifen) and improved breast cancer specific survival, and between high tumour grade and higher regional recurrence and poorer breast cancer specific survival. Further work is underway to correlate these features and other biological markers with longterm clinical outcome. Elderly patients tolerate surgery well. The risks from anaesthesia and surgery may have been overestimated and the development of local anaesthetic techniques will help. Finally, there may also be underestimation of life expectancy in elderly women. A 70 year-old woman currently has a life expectancy of 16 years, at age 80, 9 years. Even at age 90, a few additional years can be expected. Age may have been used too rigidly to decide local treatment for elderly patients with breast cancer. Comprehensive multidisciplinary assessment is needed to make informed decisions and to optimize management of elderly patients. Breast cancer therapy should be defined by a woman's physiological age rather than chronological age.
Publish with Bio Med Central and every scientist can read your work free of charge

"BioMed Central will be the most significant development for disseminating the results of biomedical research in our lifetime. " Sir Paul Nurse, Cancer Research UK

Your research papers will be:

- available free of charge to the entire biomedical community

- peer reviewed and published immediately upon acceptance

- cited in PubMed and archived on PubMed Central

- yours - you keep the copyright

Submit your manuscript here:

http://www.biomedcentral.com/info/publishing_adv.asp 